\title{
Characteristics of Haze Days Variation of Beijing in Recent 33 Years and Its Causative Factors
}

\author{
X.M. GAO \\ Satellite Surveying and Mapping Application Center, National Administration of Surveying, Mapping and \\ Geo-information, Beijing 100830 China
}

H. LIU *

Academy of Disaster Reduction and Emergency Management, Beijing Normal University, Beijing 100875 ChinarEmail:lihaha1985@126.com

\section{Z.Y. XIE}

Lanzhou Jiaotong University, Lanzhou 730070 China

\begin{abstract}
In this paper, the climatic statistical characteristics of annual number of haze days in Beijing and relationship between haze days and meteorological factors, underlying surface conditions and atmospheric aerosol are analyzed using the station observation data, land use data and remote sensing retrieval data. The results show that: haze days significantly rose from 1980 to 2012, the number of annual haze days of Beijing increased from 48 days in 1980s to 55days in 1990s, and then 73days in 2000s. From 1980 to 2012, the number of haze days presents a significant positive correlation with annual mean temperature and mean pressure, but presents a significant negative correlation with gale days, which shows that meteorological factors are important factors in haze days changing. From 1996 to 2008, the number of haze days presents a significant negative correlation with ecological land and agricultural land, but presents a significant positive correlation with construction land, residential settlements and industry and mining, traffic land, and build-up areas, which means that ecological land which is mainly covered by vegetation has an inhibitory effect on haze, while the increasing of construction land aggravates haze. From 2000 to 2012, the number of haze days presents a significant positive correlation with MODIS AOD, which shows that the increasing of air pollutant emissions promotes the formation of haze.
\end{abstract}

KEYWORD: Haze days; Meteorological factors; Underlying surface conditions; Atmospheric aerosol; Correlation analysis

\section{INTRODUCTION}

Haze is the aggregation of a large number of small dust particles, smoke and salts, it makes the air opacity and reduces the visibility below $10 \mathrm{~km}$. In 2011, the haze was selected as one of the ten important climate events, reflecting the social public has paied more attention to haze.

In recent years, scholars have carried out a number of researches about regional or national climate characteristics of haze, Wu Dui [1] analyzed long term characteristics of haze of Chinese continental from 1951 to 2005; Liu Aijun [2] analyzed the climatic characteristics and causes of haze in Guangzhou city during 1961 to 2002; In causative factors aspect, Tai and Chen [3-4] discussed from the temperature, humidity and other meteorological factors, Johansson and Lough [5-6] analyzed from the traffic flow and human activities.

Haze of Beijing attracted great attention, at present related research is lacking. This paper based on long period of meteorological observation data, land use data and remote sensing retrieval data, firstly analyzed the climatic statistical characteristics of annual number of haze days in recent 33 years, and then analyzed causative factors from the three aspects of meteorological factors, underlying surface condition and air pollution.

\section{DATA SOURCES AND PROCESSING}

Haze days data: Based on the meteorological sites observation data during 1980 2012, we got the annual haze days statistics using the most widely used 14:00 value method [7-9]. We selected Haidian site as typical city site and Shangdianzi site (located in Miyun) as a typical suburban site, and used mean value as Beijing city haze day.

Meteorological data: Annual mean value of meteorological data of Beijing from 1980 to 2011, including mean temperature, mean wind speed, number of gale days and mean pressure.

Other data such as land use areas of Beijing from 1996 to 2008, and MODIS AOD from 2000 to 2012. 


\section{RESULTS AND ANALYSIS}

\subsection{Characteristics of Haze in Beijing}

Seen from Figure 1, the number of urban haze days is much higher than that of the suburb. The average number of haze days of Haidian, Shangdianzi and Beijing during 1980 2012 are 25 days, 103 days and 60 days respectively. Haze days significantly rose from 1980 to 2012, the number of annual haze days of Shangdianzi, Haidian and Beijing increasing from 10 days, 75 days and 58 days in 1980 to 65 days, 144 days and 95 days in 2012. And the number of annual haze days changed from 12 days, 87 days and 48 days in 1980s to 19 days, days 101 days and 55 days in 1990s, and then to 42 days, 119 days and 73 days in 2000 s.

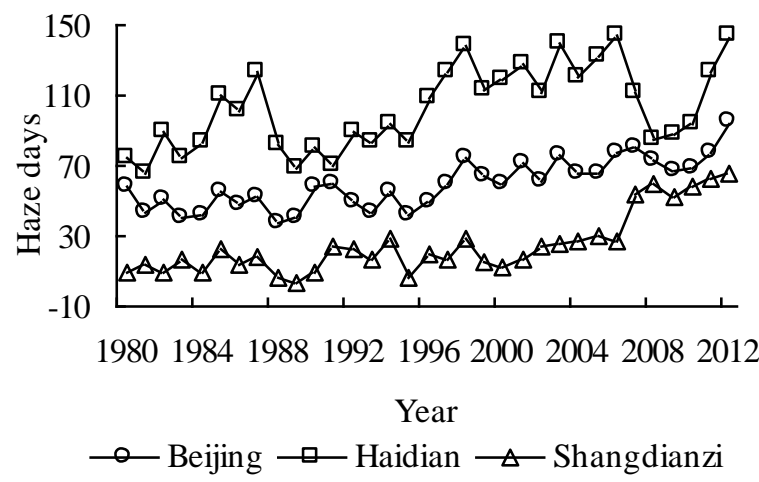

Figure 1. Beijing haze days variation during 1980 2012

Table 1. Haze days statistics during different period

\begin{tabular}{|c|c|c|c|}
\hline Sites & $1980 \sim 1990$ & $1991 \sim 2000$ & 2001 2012 \\
\hline Shangdianzi & 12 & 19 & 42 \\
\hline Haidian & 87 & 101 & 119 \\
\hline Beijing & 48 & 55 & 73 \\
\hline
\end{tabular}

\subsection{Causative factors of Haze days}

\subsubsection{Meteorological factors}

Special meteorological condition is an important cause of haze, we analyzed the relationship between haze days variations and meteorological factors such as mean temperature, mean wind speed, gale days and mean pressure.

Table 2. Correlation between haze days and meteorological

\begin{tabular}{|c|c|}
\hline Meteorological factors & Correlation coefficient \\
\hline Mean temperature & 0.460 \\
\hline Mean wind speed & -0.232 \\
\hline Gale days & -0.556 \\
\hline Mean pressure & 0.811 \\
\hline
\end{tabular}

\section{(1) Temperature}

The linear growth rate of the mean temperature of
Beijing during 1980 2012 is 0.45 degrees ${ }^{\circ} \mathrm{C} /$ decade, increasing from $11^{\circ} \mathrm{C}$ in 1980 to $13.4^{\circ} \mathrm{C}$ in 2011 (Figure 2), which show that Beijing area is getting warmer and drier in recent 30 years. Correlation analysis results (Figure 3) show that: from 1980 to 2012, the number of haze days presents a significant positive correlation with annual mean temperature, with the correlation coefficients being 0.460 .

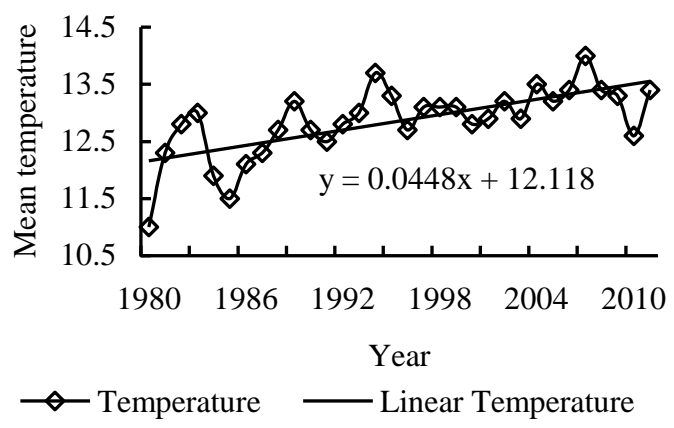

Figure 2. Mean temperature variation of Beijing

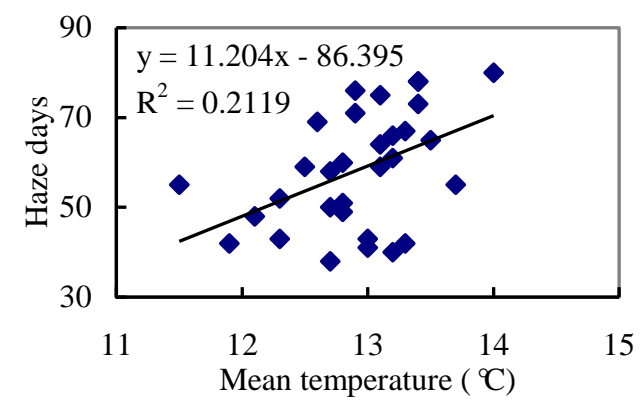

Figure 3. Scatter diagram of haze days and temperature

(2) Wind speed and Gale days

High speed wind is able to inhabit the formation and development of haze. The correlation coefficient between haze days and the mean wind speed during 1980 2011 is -0.232 , shows a negative correlation but not significantly; Seen from Figure 4, compared to the mean wind speed, gale days presents a significant negative correlation with haze days, with the correlation coefficients being -0.556 , showing that windy weather is conducive to the diffusion and transport of pollutants.

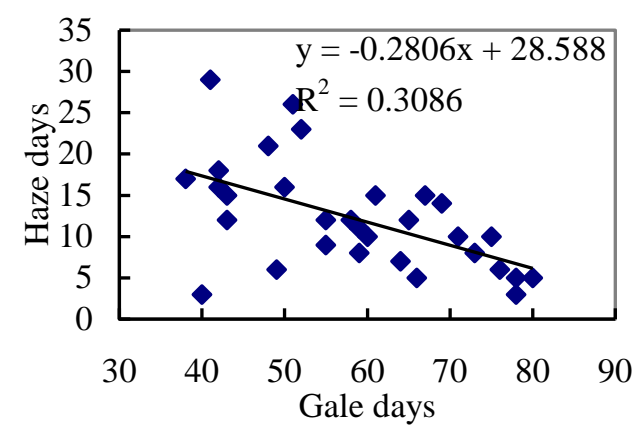

Figure 4. Scatter diagram of haze days and gale days 
(3) Pressure

Seen from the correlation between haze days and mean pressure during 1980-2011 (Figure 5), the mean pressure in Beijing falls inside the scope of $1010 \sim 1013 \mathrm{hPa}$ in recent 30 years, the number of haze days presents a significant positive correlation with annual mean pressure, with the correlation coefficients being 0.811 . That is to say, In the scope of $1010 \sim 1013 \mathrm{hPa}$, higher pressure is conducive to the formation of haze.

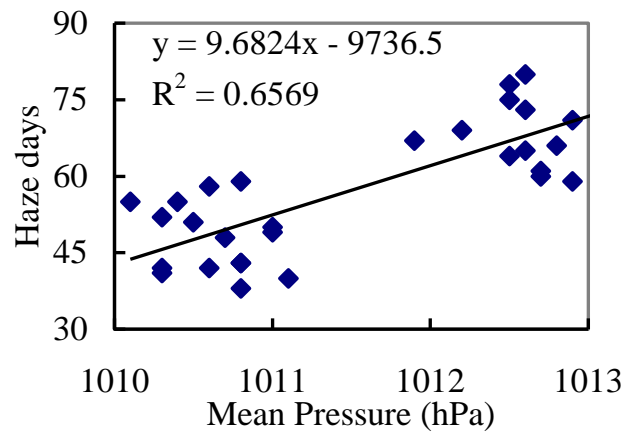

Figure 5. Scatter diagram of haze days and pressure

\subsubsection{Underlying surface condition}

Based on land use data, we analyzed the correlation between haze days and ecological land, cultivated land, construction land, residential and industrial land, traffic area and built-up area.

Table 3. Correlation between haze days and land use areas

\begin{tabular}{|c|c|}
\hline Land use type & Correlation coefficient \\
\hline Ecological land & -0.574 \\
\hline Cultivated land & -0.592 \\
\hline Construction land & 0.595 \\
\hline Residential and industrial & 0.590 \\
\hline Traffic land & 0.609 \\
\hline Built-up area & 0.876 \\
\hline
\end{tabular}

\section{(1) Ecological land}

Cultivated land decreased sharply during $1996 \sim 2008$ with a total reduction of $1122 \mathrm{~km}^{2}$, which resulted the ecological land decreased sharply with a total reduction of $444 \mathrm{~km}^{2}$. From 1996 to 2008, the number of haze days presents a significant negative correlation with ecological land and agricultural land, with the correlation coefficients being -0.574 and -0.592 respectively. It shows that ecological land which is mainly covered by vegetation has an inhibitory effect on the haze.

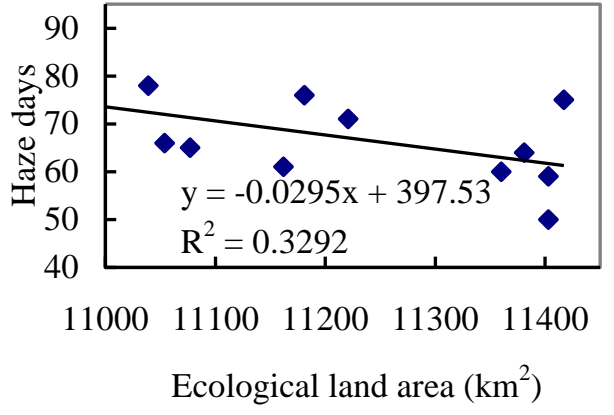

Figure 6. Scatter diagram of haze days and ecological land area

(2) Construction land

With developing of the city, residential and industrial land and traffic land increase obviously, with a total increase of $584 \mathrm{~km}^{2}$ and $144 \mathrm{~km}^{2}$ during 1996 2008, which makes the construction land increase obviously with a total increase of $742 \mathrm{~km}^{2}$. From 1996 to 2008, presents a significant positive correlation with construction land, residential settlements and industry and mining, transportation land, and build-up areas, with the correlation coefficients being $0.595,0.609,0.590$ and 0.876 respectively. It shows that the increasing of construction land aggravated the haze.

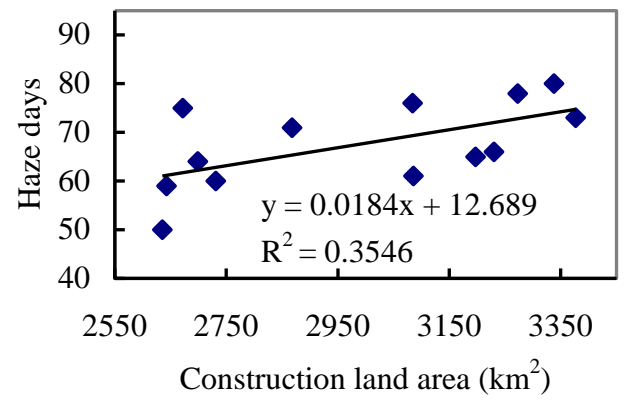

Figure 7. Scatter diagram of haze days and construction land

\subsubsection{MODIS AOD}

The increase of atmospheric pollutant emissions caused by urbanization and human activity is an important reason for the increasing of haze days. In this paper, MODIS AOD during 2000 2012 is used to analyze the correlation between haze days and air pollution.

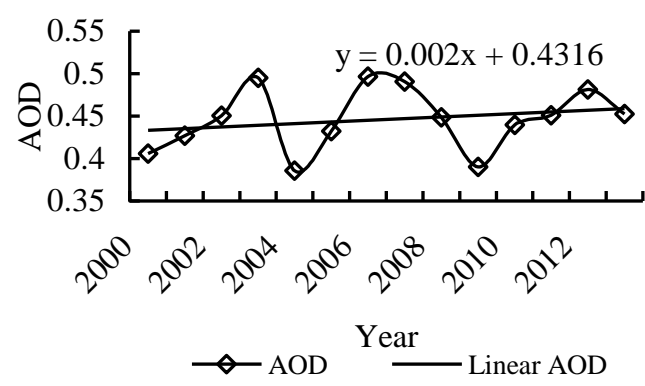

Figure 8. AOD variation of Beijing during 2000 2013 


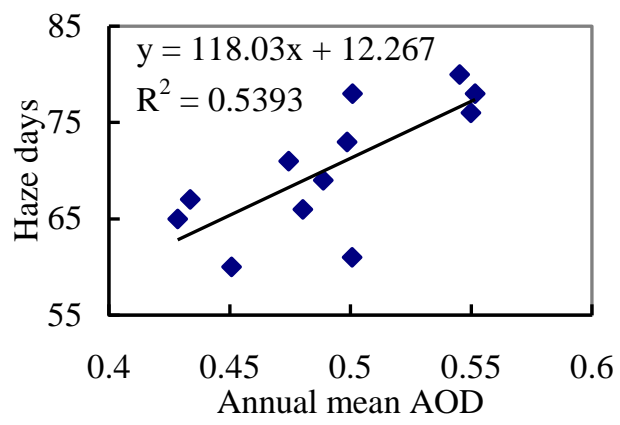

Figure 9. Scatter diagram of haze days and AOD

Seen from Figure 8, the annual mean AOD of Beijing during 2000 2012 falls inside the scope of 0.386 to 0.496 . It dumped in 2004 , and reached the upper point in 2006, the total mean value from 2000 to 2013 is 0.442 , which is much higher than the global land mean AOD (0.19) ${ }^{[10]}$. From 2000 to 2012, the number of haze days presents a significant positive correlation with MODIS AOD (Figure 9), with the correlation coefficients being 0.734. It shows that the increasing of air pollutant emissions promoted the formation of haze.

\section{CONCLUSIONS}

(1) Haze days significantly rose from 1980 to 2012 , the number of annual haze days of Beijing increasing from 58 days in 1980 to 95 days in 2012. And the average number of annual haze days changed from 48 days in 1980 s to 55 days in 1990s, and then to 73 days in 2000s.

(2) From 1980 to 2012, the number of haze days presents a significant positive correlation with annual mean temperature and mean pressure, with the correlation coefficients being 0.460 and 0.811 respectively, but presents a significant negative correlation with gale days, with the correlation coefficients being 0.556 .

(3) From 1996 to 2008, the number of haze days presents a significant negative correlation with ecological land and agricultural land, with the correlation coefficients being -0.574 and -0.592 respectively, but presents a significant positive correlation with construction land, residential settlements and industry and mining, transportation land, and build-up areas, with the correlation coefficients being $0.595,0.609,0.590$ and 0.876 respectively.

(4) From 2000 to 2012, the number of haze days presents a significant positive correlation with
MODIS AOD, with the correlation coefficients being 0.734 .

\section{ACKNOWLEDGEMENTS}

The corresponding author of this paper is Liu Hao (lihaha1985@126.com). The paper was funded by Public Science Research Programme of Surveying, Mapping and Geoinformation named 'Indicators Argumentation and Key Technology of Following Optical Mapping Satellite Applications' (No. 201412007), International Cooperation of Science project (No. S2014ZR0347) and Science and Technology Programme of National Administration of Surveying, Mapping and Geoinformation named 'The Research of Application Technical of ZY-3 satellite'.

\section{REFERENCES}

[1] Wu Dui, Wu Xiaojing, Li Fei, et al. Long-term changesin haze from 1951 to 2005 in mainland China. Proceedings of the 15th National Conference on Cloud and Precipitation and Weather.

[2] Liu Aijun, Du Yaodong, Wang Huiying. Climatic characteristics of haze in Guangzhou. Meteorological Monthly, 2004, 30(12): 68-71. (in Chinese)

[3] Tai A P, Mickley L J, Jacob D J. Correlations between fine particulate matter (PM2.5) and meteorological variables in the United States: implications for the sensitivity of PM2.5 to climate change. Atmos Envirom, 2010, 44(32):3976-3984.

[4] Chen Z H, Cheng SY, Li J B, et al. Relationship between atmospheric pollution processes and synoptic pressure patterns in northern China. Atmos Environ, 2008, 42(24): 6078-6087.

[5] Johansson C, Norman M, Burman L, et al. Road traffic emission factors for heavy metals. Atmos Environ, 2009, 43 (31): 4681-4688.

[6] Lough G C, Schauer J J, Lawson D R. Day-of-week trends in carbonaceous aerosol composition in the urban atmosphere. Atmospheric Environment, 2006, 40(22): 4137-4149.

[7] Zhao P S, Xu X F, Meng W, et al. Characteristics of hazy days in the region of Beijing, Tianjin and Hebei. China Environmental Science, 2012, 32(1): 31-36.

[8] Che H Z, Zhang X Y, Li Y, et al. Haze trends over the capital cities of 31 provinces in China, 1981-2005. Theoretical and Applied Climatology, 2009, 97: 235-242.

[9] Wu D, Mao J T, Deng X J, et al. Black carbon aerosols and their radiative properties in the Pearl River Delta region. Sci China (Series D), 2009, 52 (8): 1152-1163.

[10] Remer L A, Kleidman R G, Levy R C, et al. Global aerosol climatology from the MODIS satellite sensors. Geophysical Research, 2008, 113:18. 